\title{
MATHEMATICAL MODELLING OF HEAT TRANSFER PROBLEM FOR TWO LAYERED GYPSUM BOARD PRODUCTS EXPOSED TO FIRE
}

\author{
Aivars Aboltins $^{1}$, Harijs Kalis ${ }^{2}$, Kristaps Pulkis ${ }^{1}$, Juris Skujans ${ }^{1}$, Ilmars Kangro ${ }^{3}$ \\ ${ }^{1}$ Latvia University of Agriculture; ${ }^{2}$ Institute of Mathematics and Computer Science, \\ University of Latvia; ${ }^{3}$ Rezekne Academy of Technologies \\ aivars.aboltins@1lu.lv,kalis@lanet.lv, k.pulkis@gmail.com,ilmars.kangro@ru.lv
}

\begin{abstract}
In this paper we study the problem of the heat transfer through the two layered material of gypsum (with different densities) board products exposed to fire. This paper proposes a thermal conductivity model in two gypsum product layers for foam gypsum plate and gypsum board with different density and at high temperatures. For transfer of heat the system of 2 non-stationary partial differential equations (PDEs) is derived expressing the rate of the change of temperature $\mathrm{T}$ in every layer. The approximation of the corresponding initial boundary value problem of this system is based on the conservative averaging method (CAM) by using special splines with hyperbolic functions. This procedure allows reducing the 2-D heat transfer initial-boundary problem described by a system of 2 PDEs to the initial value problem for a system of 2 ordinary differential equations (ODEs) of the first order. The results of calculations are obtained by MATLAB.
\end{abstract}

Keywords: gypsum, heat, averaging method, splines, numerical solution.

\section{Introduction}

The standards in building construction increase and it leads to the development of new materials. Fire protection becomes a prime requirement of building regulations in many countries in the construction industry. New composite materials with good properties as thermal insulators at elevated temperatures are developed. Commercial gypsum boards are widely used in the building industry as facing materials for walls and ceilings due to their very good mechanical and thermal properties. Thermal response of gypsum materials has been experimentally and numerically studied during the past years [1-5]. Gypsum based materials are known for excellent properties in fire protection and are used as general materials to protect building structures against fire. Most of the gypsum based materials are made as low or high density boards, but it is not common to make composite materials combining low and high density layers. Boards made with different layer density can achieve better results in fire safety, thermal insulation and acoustics [6; 7]. The endothermic dehydration process that takes place at high temperatures is capable of slowing down the fire spread through gypsum board based systems. A very important role here is played by the heat transfer processes in the same material. Experimentally it is very difficult to determine, therefore, it uses the heat transfer process of mathematical modeling. There are several computation models made to predict the thermal behaviour of gypsum boards under fire conditions. They revealed the significance of using appropriate physical properties for simulating the temperature evolution inside a gypsum board when exposed to fire conditions [8-12]. As noted "no significant influence of vapour transport on temperature is observed when the phase change is omitted" [12].

The objective of the present study is to develop a mathematical model of heat transfer thought the two layered material of gypsum (foam gypsum and gypsum board) with different densities at high temperature on one of the walls.

\section{The mathematical model}

The study of heat and mass transfer through a different media becomes much more interesting due to its vast applications. We study the heat transfer processes in the two layers of gypsum material at high temperatures. We consider a gypsum board material with two layered plates in $x$-direction: foam gypsum plate $0.0525 \mathrm{~m}$ ) with density $300 \mathrm{~kg} \cdot \mathrm{m}^{-3}$ and gypsum carton plate $0.0125 \mathrm{~m}$ with density $1000 \mathrm{~kg} \cdot \mathrm{m}^{-3}$. The gypsum plate on one border is heated with temperature

$$
T=20+345 \lg (8 t+1){ }^{\circ} \mathrm{C}
$$

where $t$ - the time in minutes.

In one gypsum layer the heat and mass transfer process is analysed and described in [12; 13]. In this paper the hybrid experimental numerical method is proposed and the specific heat $c_{p}$ and thermal conductivity $K$ coefficient dependence on temperature $T$ is obtained: $K$ decreases from the value 
$0.24 \mathrm{~W} \cdot\left(\mathrm{m} \cdot{ }^{\circ} \mathrm{C}\right)^{-1}$ by $T=20^{\circ} \mathrm{C}$ to $0.12 \mathrm{~W} \cdot\left(\mathrm{m} \cdot{ }^{\circ} \mathrm{C}\right)^{-1}$ by $200{ }^{\circ} \mathrm{C}$, then $K$ increase depends on $T$ to the value 0.24 ; coefficients $c_{p}$ in these heat intervals are increasing from $1000 \mathrm{~J} \cdot\left(\mathrm{kg} \cdot{ }^{\circ} \mathrm{C}\right)^{-1}$ by $T=20^{\circ} \mathrm{C}$ to $25000 \mathrm{~J} \cdot\left(\mathrm{kg} \cdot{ }^{\circ} \mathrm{C}\right)^{-1}$ and then decreasing to 1000 . The process of diffusion and heat transfer is considered in 1-D space domain

$$
\Omega=\{(x, y, z): 0 \leq x \leq L,-\infty \leq y \leq \infty,-\infty \leq z \leq \infty\} .
$$

The domain $\Omega$ consists of two layer medium. We will consider the non-stationary problem of the linear diffusion theory for two layered piece-wise homogenous materials in the domain

$$
\Omega_{i}=\left\{(x, y, z): x \in\left(x_{i-1}, x_{i}\right), y \in(-\infty, \infty), z \in(-\infty, \infty)\right\}, i=\overline{1,2},
$$

where $H_{i}=x_{i}-x_{i-1}-$ the height of the layer $\Omega_{i}$;

$$
x_{0}=0, x_{1}=H_{1}=0.0525, x_{2}=L=H_{1}+H_{2}=0.0650, H 2=0.0125 \text {. }
$$

The rate at which the temperature of the material changes in $N$ layers is determined by the heat conduction PDE in the following form:

$$
c_{p i} \rho_{i} \frac{\partial T_{i}}{\partial t}=K_{i} \frac{\partial^{2} T_{i}}{\partial x^{2}} ; x \in\left[x_{i-1}, x_{i}\right], i=\overline{1, N}, t>0,
$$

where $c_{p i}-$ the specific heat;

$K_{i}, \rho_{i}$ - the heat conductivity and the density of the gypsum material.

We assume that the coefficients $c_{p}, K$ in the PDEs are dependent of the temperature $T$ similarly as in [13] (we use linear interpolation, see Fig. 1, 2).

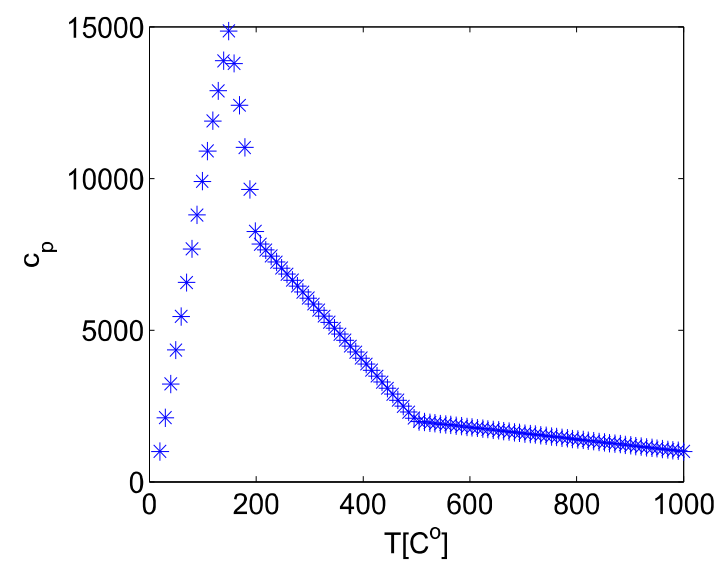

Fig. 1. Specific heat $c_{p}$ depending on temperature $T$

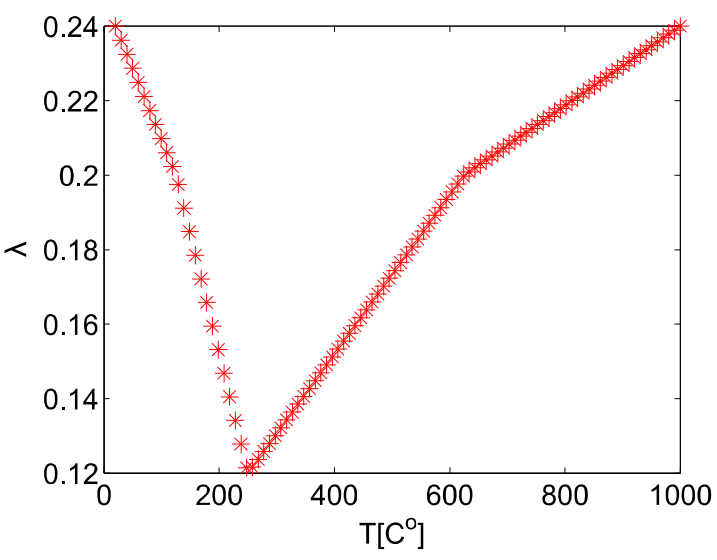

Fig. 2. Thermal conductivity $K$ depending on temperature $T$

In the case of two layers $(N=2)$ we obtain the system of two PDEs

$$
\left\{\begin{array}{l}
D_{1}(T) \frac{\partial^{2} T_{1}(x, t)}{\partial x^{2}}=\frac{\partial T_{1}(x, t)}{\partial t}, \\
D_{2}(T) \frac{\partial^{2} T_{2}(x, t)}{\partial x^{2}}=\frac{\partial T_{2}(x, t)}{\partial t},
\end{array}\right.
$$

where $\quad D_{i}(t)=\frac{K_{i}(t)}{\rho_{i} c_{p i}(T)}, i=1,2-$ the thermal diffusion coefficients depending on $T$.

For the initial condition for $t=0$ we give $T_{1}(x, 0)=T_{2}(x, 0)=T_{0}$, where $T_{0}=20^{\circ} \mathrm{C}$.

We use following boundary and continuous conditions: 


$$
\left\{\begin{array}{l}
D_{1}(T) \frac{\partial T_{1}(0, t)}{\partial x}-\alpha\left(T_{1}(0, t)-T_{a}\right)=0, T_{2}(L, t)=T_{b}+T_{l}(t), \\
T_{1}\left(x_{1}, t\right)=T_{2}\left(x_{1}, t\right), D_{1}(t) \frac{\partial T_{1}\left(x_{1}, t\right)}{\partial x}=D_{2}(t) \frac{\partial T_{2}\left(x_{1}, t\right)}{\partial x},
\end{array}\right.
$$

where $\alpha-$ are the constant mass transfer coefficients;

$T_{l}(t)=345 \lg (8 t+1)$ in minutes;

$T_{a}=T_{b}=20^{\circ} \mathrm{C}$.

\section{CAM with integral hyperbolic splines in two layers}

The method of conservative averaging (CAM) by using the special integral splines with hyperbolic trigonometric functions is openly discussed in papers [15]. The CAM procedure allows reducing the problem to an initial problem for the system of ODEs. Using the averaged method with respect to $x$ we have

$$
T_{i}(x, t)=T_{i v}(t)+m_{i}(t) \frac{0.5 H_{i} \sinh \left(a_{i}\left(x-\bar{x}_{i}\right)\right)}{\sinh \left(0.5 a_{i} H_{i}\right)}+e_{i}(t)\left(\frac{\cosh \left(a_{i}\left(x-\bar{x}_{i}\right)\right)-A_{i}}{8 \sinh ^{2}\left(0.25 a_{i} H_{i}\right)}\right),
$$

where $T_{i v}(t)=H_{i}^{-1} \int_{x_{i-1}}^{x_{i}} T_{i}(x, t) d x$;

$$
\begin{aligned}
& \bar{x}_{i}=\left(x_{i-1}+x_{i}\right) / 2, x \in\left[x_{i-1}, x_{i}\right] ; \\
& A_{i}=\frac{\sinh \left(0.5 a_{i} H_{i}\right)}{0.5 a_{i} H_{i}}, i=1 ; 2 .
\end{aligned}
$$

We can see if the parameters $a_{1}>0, a_{2}>0$ tend to zero, then the limit is the integral parabolic spline (A. Buikis [14]):

$$
T_{i}(x, t)=T_{i v}(t)+m_{i}(t)\left(x-\bar{x}_{i}\right)+e_{i}(t)\left(\frac{\left(x-\bar{x}_{i}\right)^{2}}{H_{i}^{2}}-\frac{1}{12}\right) .
$$

The unknown functions $m_{i}(t), e_{i}(t)$ can be determined from conditions (3):

1. For $x=0 D_{1}(T)\left(m_{1} d_{1}-e_{1} k_{1}\right)-\alpha\left(T_{1 v}-m_{1} H_{1} / 2+e_{1} b_{1 x}-T_{a}=0\right.$

2. For $x=L T_{2 v}+0.5 m_{2} H_{2}+e_{2} b_{2 x}+T_{c}(t), T_{c}(t)=T b+T_{l}(t)$;

3. For $x=x_{1} T_{1 v}+0.5 m_{1} H_{1}+e_{1} b_{1 x}=T_{2 v}-0.5 m_{2} H_{2}+e_{2} b_{2 x}$.

$$
D_{1}(T)\left(m_{1} d_{1}+e_{1} k_{1}\right)=D_{2}(t)\left(m_{2} d_{2}-e_{2} k_{2}\right),
$$

where $d_{i}=0.5 H_{i} a_{i} \operatorname{coth}\left(0.5 a_{i} H_{i}\right)$,

$$
\begin{aligned}
k_{i} & =0.25 a_{i} \operatorname{coth}\left(0.25 a_{i} H_{i}\right), \\
b_{i x} & =\frac{\cosh \left(0.5 a_{i} H_{i}\right)-A_{i}}{8 \sinh ^{2}\left(0.25 a_{i} H_{i}\right.}, i=1 ; 2 .
\end{aligned}
$$

Therefore

$$
\begin{aligned}
& m_{2}=m_{21} T_{1 v}+m_{22} T_{2 v}+m_{23} T_{c}(t)+m_{24} T_{a}, e_{2}=e_{21} T_{1 v}+e_{22} T_{2 v}+e_{23} T_{c}(t)+e_{24} T_{a}, \\
& m_{1}=m_{11} T_{1 v}+m_{12} T_{2 v}+m_{13} T_{c}(t)+m_{14} T_{a}, e_{1}=e_{11} T_{1 v}+e_{12} T_{2 v}+e_{13} T_{c}(t)+e_{14} T_{a}, \\
& \text { where } m_{21}=-b_{2 x}\left(1+b_{12}\right) / \mathrm{det}, m_{22}=\left(b_{2 x}-b_{11}\right) / \mathrm{det}, m_{23}=b_{11} / \mathrm{det}, m_{24}=b_{2 x} b_{12} / \mathrm{det}, \\
& e_{21}=0.5 H_{2}\left(1+b_{12}\right) / \mathrm{det}, e_{22}=-\left(0.5 H_{2}+b_{10}\right) / \mathrm{det}, e_{23}=b_{10} / \mathrm{det}, e_{24}=-0.5 H_{2} b_{12} / \mathrm{det}, \\
& m_{11}=b_{7} m_{21}-b_{8} e_{21}+b_{9}, m_{12}=b_{7} m_{22}-b_{8} e_{22}, m_{13}=b_{7} m_{23}-b_{8} e_{23}, m_{14}=b_{7} m_{24}-b_{8} e_{24}-b_{9},
\end{aligned}
$$




$$
\begin{aligned}
& e_{11}=m_{11} / b_{1}-b_{13}, e_{12}=m_{12} / b_{1}, e_{13}=m_{13} / b_{1}, e_{14}=m_{14} / b_{1}+b_{13}, \\
& b_{1}=\frac{k_{1}+\text { alf } \cdot b_{1 x}}{d_{1}+0.5 \text { alf } H_{1}}, \text { alf }=\alpha_{Q} / D_{1}, b_{2}=\frac{\text { alf }}{d_{1}+0.5 \text { alfH }}, b_{3}=\frac{D_{2}}{D_{1} k_{1}}, b_{4}=0.5 H_{2}+b_{3} d_{2} b_{1 x}, \\
& b_{5}=b_{2 x}+b_{3} k_{2} b_{1 x}, b_{6}=0.5 H_{1}-b_{1 x} / p_{1}, p_{1}=k_{1} / d_{1}, b_{7}=\frac{p_{1} b_{1} b_{3} d_{2}}{p_{1}+b_{1}}, b_{8}=\frac{p_{1} b_{1} b_{3} k_{2}}{p_{1}+b_{1}}, \\
& b_{9}=\frac{p_{1} b_{2}}{p_{1}+b_{1}}, b_{10}=b_{4}+b_{6} b_{7}, b_{11}=b_{5}+b_{6} b_{8}, b_{12}=b_{6} b_{9}, b_{13}=b_{2} / b_{1} .
\end{aligned}
$$

From (2) follows the nonlinear system of ODEs

$$
\left\{\begin{array}{l}
2 D_{1}(t) k_{1} e_{1}(t) / H_{1}=\frac{\partial T_{1 v}(t)}{\partial t}, \\
2 D_{2}(t) k_{2} e_{2}(t) / H_{2}=\frac{\partial T_{2 v}(t)}{\partial t}, \\
T_{1 v}(0)=T_{2 v}(0)=T_{0},
\end{array}\right.
$$

or

$$
\left\{\begin{array}{l}
\dot{T}_{1 v}=b_{11} T_{1 v}+b_{12} T_{2 v}+f_{1}+p_{1}(t), \\
\dot{T}_{2 v}=b_{21} T_{1 v}+b_{22} T_{2 v}+f_{2}+p_{2}(t), \\
T_{1 v}(0)=T_{2 v}(0)=T_{0},
\end{array}\right.
$$

where $b_{i, j}=2 D_{i} k_{i} e_{i, j} / H_{i}$,

$$
\begin{aligned}
& f_{i}=2 D_{i} k_{i}\left(e_{i 3} T_{b}+e_{i 4} T_{a}\right), \\
& p_{i}(t)=2 D_{i} k_{i} e_{i 3} T_{l}(t), i, j=1 ; 2 .
\end{aligned}
$$

where $W(t), W_{0}, F, P$ - the 2-order vector-column with elements $\left(T_{1 v}(t), T_{2} v(t)\right),\left(T_{0}, T_{0}\right),\left(f_{1}, f_{2}\right)$, $\left(p_{1}, p_{2}\right)$,

$A$ is the 2-order matrix

$$
A=\left(\begin{array}{ll}
b_{11} & b_{12} \\
b_{21} & b_{22}
\end{array}\right) .
$$

For constant heat parameters the averaged solution is

$$
W(t)=W_{1}(t)+W_{2}(t),
$$

where $\quad W_{1}(t)=\exp (A t) W_{0}-(E-\exp (A t)) A^{-1} F-$ the analytical solutions of the ODEs system $\dot{W}_{1}(t)=A W_{1}(t)+F, W_{1}(0)=W_{0}$.

Splitting the vector $p(t)$ in the form $p(t)=g(t) E, E=(1,1)$, the solution of the ODEs system $\dot{W}_{2}(t)=A W_{2}(t)+g(t) E, W_{2}(0)=0$ we can obtain using the spectral decomposition of the matrix A:

$$
\begin{gathered}
A=V D V_{1}, V_{1}=V^{-1}, W_{2}(t)=V R(t), \\
\dot{R}(t)=D R(t)+g(t) V_{1} E, R(0)=0, R(t)=I(t) V_{1} P_{0}, \\
I(t)=\int_{0}^{t} \exp (D(t-\tau)) g(\tau) d \tau
\end{gathered}
$$


where $D$ - the diagonal matrix with negative discrete eigenvalues $-k_{i}, i=\overline{1,4}$,

$V$ - the matrix of eigenvectors in the column, $R(t)$ is the column-vector.

If $g(t)=\ln (8 t+1)$ then

$$
\begin{gathered}
I_{i}(t)=\int_{0}^{t} \exp \left(k_{i}(t-\tau)\right) g(\tau) d \tau= \\
=\frac{1}{\left|k_{i}\right|}\left(\ln (8 t+1)+\exp \left(-(t+1 / 8)\left|k_{i}\right|\right)\left(E_{i}\left(\left|k_{i}\right| / 8\right)-E_{i}\left(\left|k_{i}\right|(1+1 / 8)\right)\right)\right),
\end{gathered}
$$

where $E_{i}(q)$ - the integral exponential ([16], formula 3.352-3 in 325.p).

The temperature depending solution $W(t)$ can be obtained with Matlab solver "ode15s".

\section{Some numerical results}

For the calculations we use the discrete grid values $x_{j}=j h, j=\overline{0, N_{x}}, N_{x} h=L, t_{n}=n \tau$, $n=\overline{0, N_{t}}, N_{t} \tau=t_{f}$ and the parameters $N_{t}=100, T_{0}=20^{\circ} \mathrm{C}, T_{a}=20^{\circ} \mathrm{C}, T_{c}(t)=20+345 \lg (8 t+1)^{\circ} \mathrm{C}$, $t \in\left[0, t_{b}\right], t_{b}$ is the maximal heating time.

The stationary solutions are obtained in the time $t_{f}>t_{b}$ with the maximal temperature $T\left(L, t_{f}\right)=678.43^{\circ} \mathrm{C}$.

The results of calculation for $t_{t}=2000 \mathrm{~s}, t_{b}=600 \mathrm{~s}$ are represented in Fig. 3 and 4. with $T\left(0, t_{f}\right)=$ 139.94, $T\left(h_{1}, t_{f}\right)=150.42, T_{1 v}=139.08, T_{2 v}=387.10$, (the temperature in the first layer, gypsum plate is nearly constant). values.

The parameters $a_{1}=20, a_{2}=10$ are obtained for the minimal value of maximal error for averaging

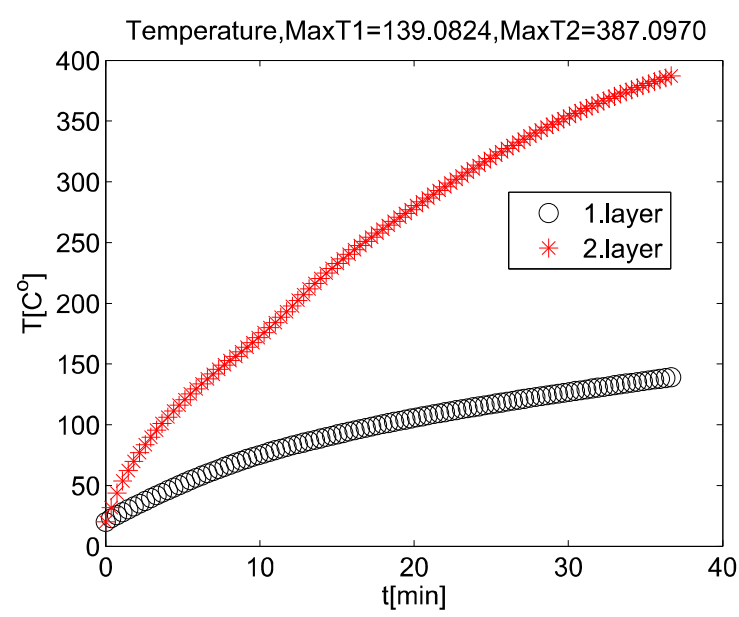

Fig. 3. Averaging temperature depending on $t$ for $t_{f}=2000 \mathrm{~s}$

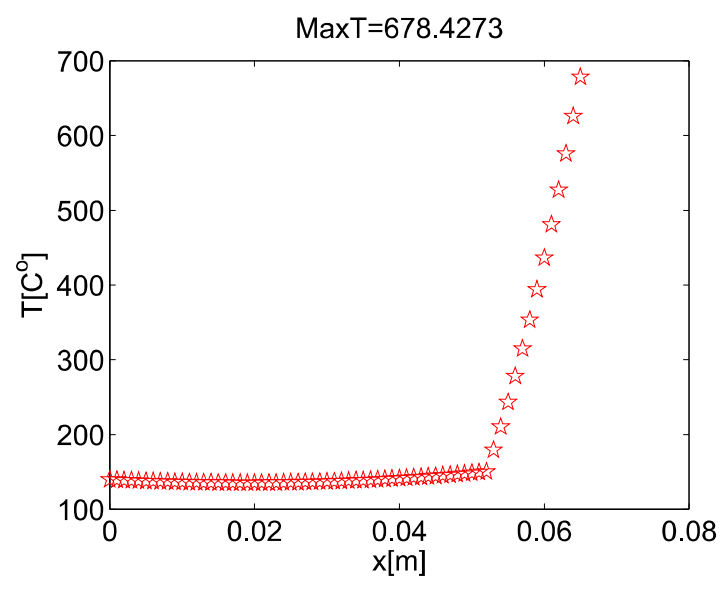

Fig. 4. Temperature depending on $x$ for $t_{f}=2000 \mathrm{~s}$

For numerical experiment we use also backward orientation: for gypsum plate $H_{2}=0.0525 \mathrm{~m}$ with density $\rho_{2}=300 \mathrm{~kg} \cdot \mathrm{m}^{-3}$ gypsum carton plate $H_{1}=0.0125 \mathrm{~m}$ with density $\rho_{1}=1000 \mathrm{~kg} \cdot \mathrm{m}^{-3}$, $a_{1}=20, a_{2}=10$. The results of calculation are represented in Fig. 5 and 6 with $T\left(0, t_{f}\right)=100.27$, $T\left(H_{1}, t_{f}\right)=479.73, T\left(L, t_{f}\right)=678.43, T_{1 v}=283.88, T_{2 v}=569.15$ (the temperature for $x=0$ in this case is smaller also in direct orientation).

For $t_{t}=6000 \mathrm{~s}, t_{b}=4800 \mathrm{~s}$ with the maximal temperature $988.37^{\circ} \mathrm{C}$ the results of calculation are represented in the Fig. 7-10 with $T\left(0, t_{f}\right)=229.87, T\left(H_{1}, t_{f}\right)=297.86, T\left(L, t_{f}\right)=988.37, T_{1 v}=263.09$, $T_{2 v}=642.08$, (direct orientation), $T\left(0, t_{f}\right)=183.64, T\left(H_{1}, t_{f}\right)=910.94, T\left(L, t_{f}\right)=988.37, T_{1 v}=2547.20$, $T_{2 v}=949.63$ (backward orientation). 


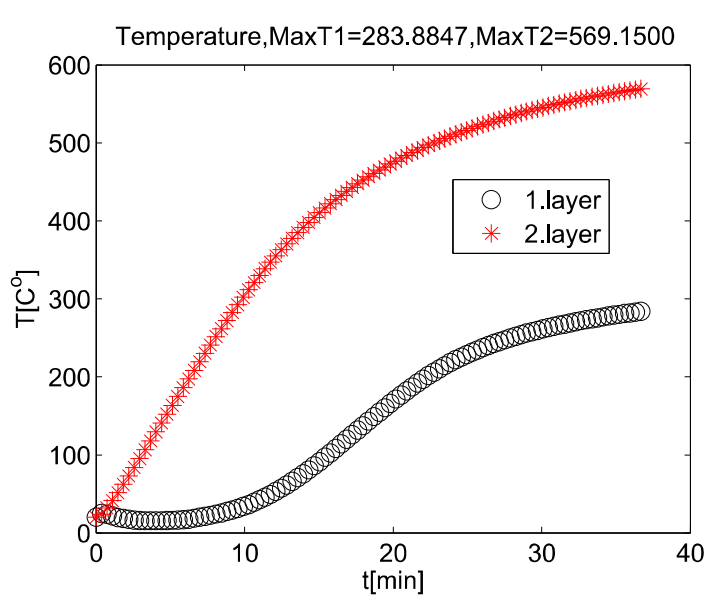

Fig. 5. Backward averaging temperature depending on $t$ for $t_{f}=2000 \mathrm{~s}$

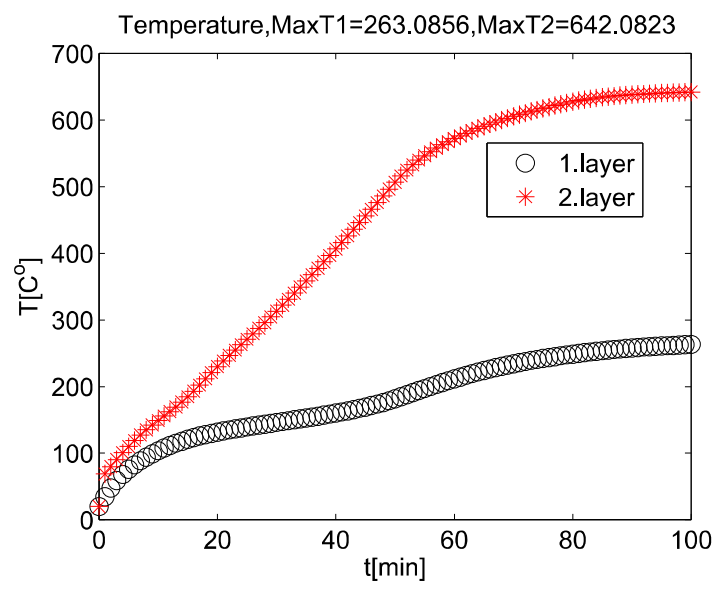

Fig.7. Averaging temperature depending on $t$ for $t_{f}=6000 \mathrm{~s}$

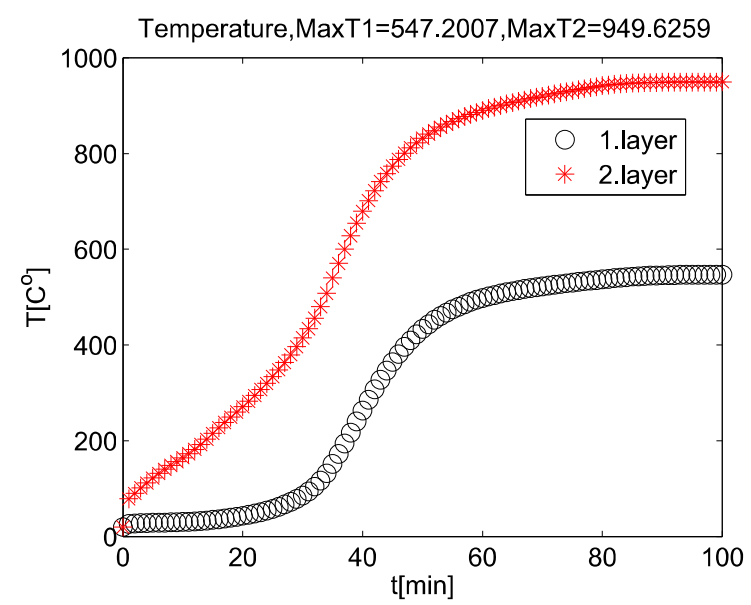

Fig. 9. Backward averaging temperature depending on $t$ for $t_{f}=6000 \mathrm{~s}$

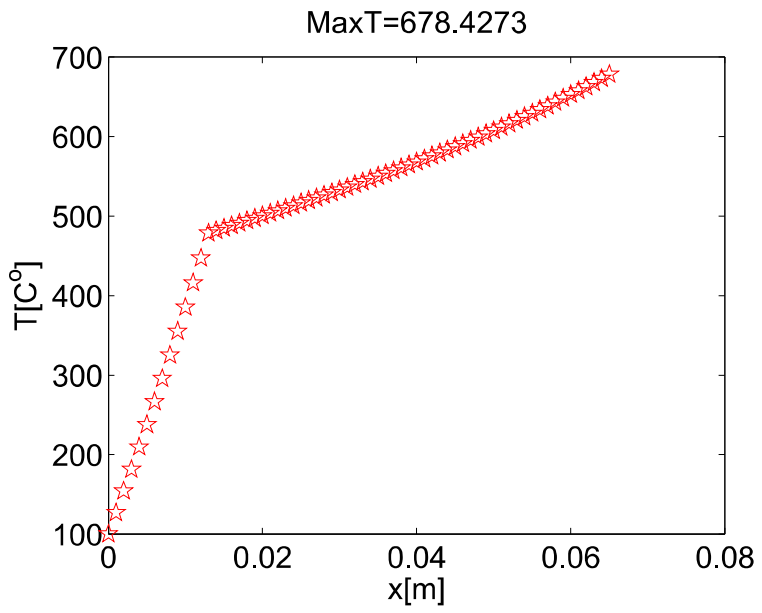

Fig. 6. Backward temperature depending on $x$ for $t_{f}=2000 \mathrm{~s}$

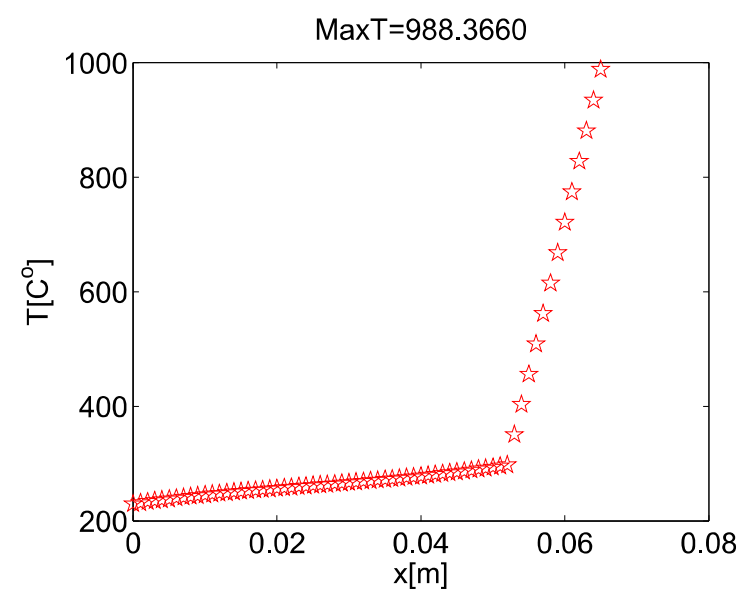

Fig. 8. Temperature depending on $x$ for $t_{f}=6000 \mathrm{~s}$

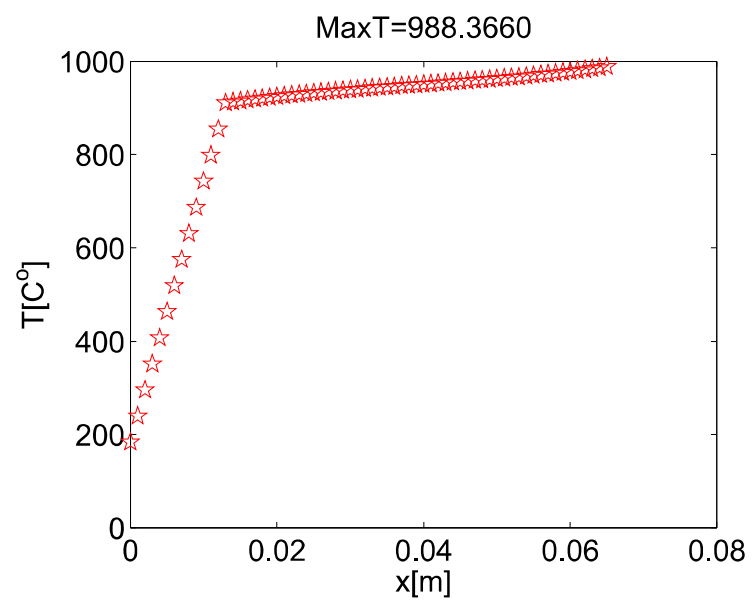

Fig. 10. Backward temperature depending on $x$ for $t_{f}=6000 \mathrm{~s}$ 


\section{Conclusions}

1. For transfer of heat in two gypsum layers the system of 2 PDEs for determination the temperature $T$ in every layer is considered.

2. The approximation of the corresponding initial boundary value problem of the system of PDEs is based on the conservative averaging method (CAM).

3. CAM is used with new hyperbolic type splines. For these splines the best parameter for minimal error is calculated. This method can be used for solution of the multi dimension 3D problem of PDEs.

4. The problem of the system of PDEs with constant coefficients is approximated on the initial value problem of a system of linear and nonlinear ODEs of the first order, where it is solved analytically and with Matlab solvers.

5. Such a procedure allows to obtain a simple engineering algorithm for solving mass transfer equations for different substances in layered domain.

6. The results of the numerical experiments can give some new physical conclusions about the drying process in gypsum board materials.

\section{Acknowledgments}

This work was partially supported by the grant 623/2014 of the Latvian Council of Science and the European Regional Funding for the project SAM 1.1.1.1./A/16/004.

\section{References}

1. Oliver A., Thermal characterization of gypsum boards with PCM included: thermal energy storage in buildings through latent heat, Energy Build. vol. 48, 2012, pp. 1-7.

2. Serrano S, Barreneche C., Fernández A., Farid M., Cabeza L., Composite gypsum containing fatty-ester PCM to be used as constructive system: thermophysical characterization of two shapestabilized formulations, Energy Build, vol.86, 2015, pp. 190-193.

3. Borreguero A., Sánchez M., Valverde J., Carmona M., Rodríguez J., Thermal testing and numerical simulation of gypsum wall boards incorporated with different PCMs content, Appl. Energy, vol. 88, 2011, pp. 930-937.

4. Sayyara M., Weerasiri R., Soroushiana P., Lu J., Experimental and numerical study of shapestable phase change nanocomposite toward energy-efficient building constructions, Energy Build., Vol. 75, 2014, pp. 249-255.

5. Lai C., Chen R., Lin C., Heat transfer and thermal storage behaviour of gypsum boards incorporating micro-encapsulated PCM, Energy Build. vol. 42, 2010, pp.1259-1266.

6. Serranoa S., Barrenechea C., Navarroc A., Hauriec L., Fernandez A., Cabezaa A.,Use of multilayered PCM gypsums to improve fire response. Physical, thermal and mechanical characterization, Energy and Buildings vol.127, 2016, pp.1-9

7. Kontogeorgos D., Founti M. Gypsum board reaction kinetics at elevated temperatures, Thermochimica Acta, vol. 529, 2012,pp. 6-13

8. Wakili K., Hugi E., Wullschleger L., Frank T., Gypsum board in fire - modeling and experimental validation, Journal of Fire Sciences vol. 25, 2007, pp. 267-282.

9. Wullschleger L., Wakili K., Numerical parameter study of the thermal behavior of a gypsum plaster board at fire temperatures, Fire and Materials, vol. 32, 2008, pp. 103-119.

10. Kontogeorgos D., Founti M., Numerical investigation of simultaneous heat and mass transfer mechanisms occurring in a gypsum board exposed to fire conditions, Applied Thermal Engineering, vol. 30, 2010. pp.1461-1469.

11. Kolaitis D., Founti M. Development of a solid reaction kinetics gypsum dehydration model appropriate for CFD simulation of gypsum plasterboard wall assemblies exposed to fire Fire Safety Journal vol.58, 2013, pp. 151-159

12. Weber B. Heat transfer mechanisms and models for a gypsum board exposed to fire, International Journal of Heat and Mass Transfer vol.55, 2012, pp. 1661-1678

13. Rahmanian I,. Wang Y.C., A combined experimental and numerical method for extracting temperature-dependent thermal conductivity of gypsum boards.Construction and Building Materials 26 (2012) pp. 707-722. 
14. Buike M. and Buikis A. Modelling 3-D transport processes in anisotropic layered stratum by conservative averaging method. WSEAS Transactions on Heat and Mass Transfer, 2006, vol.1, Nr. 4, 430-437.

15. Buikis A., Kalis H., and Kangro I. Special Hyperbolic type spline for mass transfer problems in multi-layer 3-D domains. Mathematical and Computational Methods in Applied Sciences. Proc. of the 3-rd int. conf. on Applied,Numerical and Cmputational Mathematics (ICANCM'15), Sliema, Malta,aug.17-19,2015, 25-34.

16. Gradshtein I.S., Ryhzik I.M.. Table of integrals, summ, series and multiplicatives. Nauka Press, Moscou, 1962.,in Russian. 